\title{
Division of the Self: Life After Death and the Binary Soul Doctrine
}

\author{
Peter Novak \\ LaPorte, IN
}

\begin{abstract}
Ancient Egyptians believed that each individual had two souls, a $b a$ and a $k a$, which separated at death unless steps were taken to prevent this division. Egyptian descriptions of the $b a$ and $k a$ are strikingly similar to modern scientists' descriptions of the conscious and unconscious halves of the human psyche. Many other cultures all over the globe believed in two souls, one like the conscious, the other like the unconscious, which separated at death. Many cultures held that one soul would go on to reincarnate, while the other would become trapped in a dreamlike netherworld. Some believed that this division could be prevented or reversed, while others saw the division as being inevitable. The two stages of near-death experiences, a detached, objective, and dispassionate "black void" followed by a subjective, relationship-oriented, and emotionally intense "realm of light," reflect the distinctions between the conscious mind and the unconscious mind. The "darkness" stage seems to be experienced exclusively through the conscious half of the psyche, while the "light" stage seems to be experienced exclusively through the unconscious, as if the two were operating independently during these episodes. A similarly polarized dichotomy can be found in the accounts of reincarnation, of the Realm of Bewildered Souls, of the void between lives, of the behavior of ghosts and apparitions, and in statements about the afterlife by parapsychologists. The "Binary Soul Doctrine" hypothesis, that the two halves of the psyche separate after death, offers a consistent explanation for these afterlife phenomena.
\end{abstract}

KEY WORDS: binary soul doctrine; survival of death; near-death experience; reincarnation.

Today, many believe they truly know what awaits us on the other side of death's door, while others are just as convinced that this, the greatest of mysteries, will never be solved. Adding fuel to the latter argument, disagreement remains among those who assert they do

Peter Novak is the free-lance author of The Division of Consciousness: The Secret Afterlife of the Human Psyche. Reprint requests should be addressed to Mr. Novak at 1428 Illinois Avenue, LaPorte, IN 46350 (e-mail: division@divisiontheory.com). 
know; and contradictions abound between afterlife models of different groups. But long ago, this was not the case. Instead, virtually the same model of death was once held in common by cultures all across the globe. And this lost vision of the afterlife, which appears to be consistent with the latest findings in modern psychology, neuropsychology, and near-death studies, carries profound implications for modern afterlife research.

\section{The Ancient Binary Soul Doctrine}

From Egypt to India to Hawaii to America, cultures all over the world once believed very much the same thing: that people had not one, but two souls, and that those two souls tended to separate from one another at death, each going on to an entirely different afterlife experience. But if those divided parts could be reunited, the person would be restored to wholeness, thereafter enjoying an eternal divine existence. Alien as it is to modern ears, this binary soul concept was probably the closest thing this planet has ever had to a single world religion. Its origins are prehistoric; it seems to have already been in existence at the dawn of civilization. Yet it uses the same model of the self described by modern psychologists and neuropsychologists, and it predicts the very conditions described by modern research into NDEs, past-life memories, apparitions, and other afterlife phenomena.

This ancient tale of dividing souls, or something very similar to it, is found repeated in culture after culture, turning up again and again in early afterlife traditions all over the globe. Ancient Egypt, Israel, Persia, Greece, India, Islam, China, Australia, Hawaii, Alaska, the Dakota tribe of North America, and dozens of other indigenous peoples of North and South America, Asia, Europe, and Africa all subscribed to such a Binary Soul Doctrine. The specific details are sometimes quite different, but the core message is always the same: that people possess two souls that can and often do separate at death, each going off into a different afterlife experience. And these otherwise very different and alien cultures consistently described these two souls in similar ways, uncannily paralleling today's scientists' descriptions of the conscious and unconscious. Again and again, the reader finds one soul being described as objective, masculine, rational, intelligent, active, and possessing independent free will, while the other is described as subjective, feminine, emotional, responsive, and in possession of the memory records. 


\section{The Egyptian Version of the Binary Soul Doctrine}

From its earliest days, Egyptian culture, commonly recognized as the earliest civilization in history, embraced the legend of Osiris, his doctrine of eternal life becoming the center focus of their religion. Osiris was reported to have divided into pieces when he died, but when those fragments were reassembled, he became restored to a divine and eternal existence. This model of death was reflected in the Egyptian doctrine of the division of the two $b a$ and $k a$ souls after death, and the expectation that if the $b a$ and $k a$ could be reunited, the person would then be fully reconstituted and perfected, transfigured into a divine being like Osiris himself.

This was extremely old information, even then: many of the prayers of the Egyptian Book of the Dead (Budge, 1967) were already so ancient that the scribes who copied them were sometimes uncertain just what those prayers were supposed to mean. Those prayers reveal much about the afterlife beliefs of Egyptians, strongly suggesting that ancient Nile culture was aware of a subtle truth that our scientists have only rediscovered and verified in recent years: that the human mind is differentiated into two distinct components, the conscious mind, which possesses the rational intellect and the autonomous free will, and the unconscious mind, which possesses the emotions and the memory (Schiffer, 1998). Ancient Egyptians believed much the same thing, that human beings possess not one but two souls, two distinct nonmaterial, psychological components that, they believed, both survived death. While Egyptians also distinguished and named a number of other different elements of the individual, only two of these, the $b a$ and $k a$, were thought capable of surviving after death (El Mahdy, 1989).

A third soul-like element, the $k h u$ or $a a k h u$, was also often said to exist after death, but this soul existed only potentially, created out of the reunion of the $b a$ and $k a$ after death. The aakhu was not an additional, third soul one also possessed; rather, it was an entirely new kind of soul one could potentially become, one which did not exist at all prior to death, and after death, it came into existence only if all went well with the $b a-k a$ reunion.

The Ba as the Conscious Mind. Like the conscious and unconscious of today's science, both the $b a$ and $k a$ were considered to be integral elements of the self. In fact, both the $b a$ and $k a$ carried, independently of one another, the meaning of "the self." The $b a$ was the living, conscious self. Just like the conscious mind of today's psychology, the $b a$ was considered to possess its own independent and autonomous 
free will, focused self-conscious awareness, intelligence, and the ability to move and communicate (Ries, 1987). Like the conscious mind, the $b a$ embodied the objective perspective, viewing the outer world as an object separate and distinct from itself. Like the conscious mind, each $b a$ was the lone master of its own decisions, lone witness of its own inner domain; the $b a$ was the inner, private self, the utterly alone experience of being that can never be truly shared with another (Wheeler, 1999). And like the conscious mind, the $b a$ was conceived of as the fount of intellect: while the $k a$ was credited with making the body talk, the $b a$ was what caused the words to make sense (Effland, 1999).

But quite unlike modern scientists' depiction of the conscious mind, the $b a$ was also credited with permanent possession of both the spark of life force and the power of motion and animation (Ries, 1987). The $b a$ could never die, never cease to exist, never cease to be conscious and aware (Budge, 1967). The $b a$ would always be alive and would always be aware of its own existence. But its sense of continuity, the coherence of its sense of self, was quite a different matter. That was not guaranteed, and all the funerary rituals and efforts of ancient Egyptians had but one purpose: to maintain the coherency of that self-experience while passing through the doors of death (Wheeler, 1999).

The Ka as the Unconscious Mind. Unlike the $b a$, the $k a$ could cease to exist (El Mahdy, 1989). In a twist that has confused scholars for centuries, the $k a$, a different element altogether, was somehow also considered to be "the self." Actually, $k a$ is the Egyptian word for "you," a pun-like choice of words that emphasizes the $k a$ 's role in relationships (Wheeler, 1999). In a great many respects, the $k a$ parallels modern scientists' concept of the unconscious half of the human psyche (Crehan, 1976). Like the unconscious, the $k a$ was associated with dream activity during sleep (Effland, 1999). Like the unconscious, the $k a$ was thought to be able to work in secret, without its owner's knowledge, even able to deceive or betray its owner. Like the unconscious, the ka could either work for or against its owner (Wheeler, 1999). Like the unconscious, the $k a$ was thought to contain a record, or be a model, of all one's personal memories and subjective emotions, and thus, one's sense of self-identity (El Mahdy, 1989). Like the unconscious, the $k a$ was polarized towards a subjective or intersubjective orientation, providing one's ability to relate to and interact with others; it was, like the unconscious, the source of one's subjective sense of belonging, of living connection with others. And therefore, it was, again like the unconscious, thought to be the source of one's sense of morality and conscience. And like 
the unconscious, the $k a$ was considered to be moldable, changeable, and potentially unreliable (Wheeler, 1999). Analysis of Egyptian art also suggests identifying the $k a$ with the unconscious: just as the unconscious is thought of as the equal but opposite dark interior to the conscious mind's lighted exterior, so too the $k a$ was often depicted in art as a blackened reverse image of the person (Effland, 1999).

The $k a$ was said to be the person's "double"; it embodied the pattern of one's person by molding itself into a perfect image or likeness of the individual and his character ( $\mathrm{El} \mathrm{Mahdy,} \mathrm{1989).} \mathrm{In} \mathrm{fact,} \mathrm{the}$ ancient Egyptian word $k a$ still lives on in our language, in words like "character" and "charisma" (Wheeler, 1999). Like the unconscious, the $k a$ preserved within itself a complete record or pattern of one's life history and personal nature; in other words, it contained the shapes of one's memories, on which the continuity and coherence of one's sense of self-identity depends. It constituted a complete database of all one's individual characteristics, disposition, and attributes, all one's feelings, emotions, needs, desires, fears, expectations, and appetites (El Mahdy, 1989). In short, the $k a$ was the "form" that gave shape to the $b a$ 's "substance." The $k a$ was closely associated with the concept of form and image; it was what allowed different shapes to be taken (Ries, 1987).

The Relationship of the Ba and Ka During Life. The one thing the $k a$ lacked was sustenance. The $k a$ was thought not to possess its own inherent spark of life force that could keep it eternally alive, energized, and active, so it needed to look to other, outside sources to acquire a regular supply of its necessary nourishment (Davies, 1987). The $b a$, which was thought to possess that eternally-living spark of life force, was said to nestle inside the $k a$ during one's human life (Davies, 1987); the $k a$ held the $b a$ within it like a cup holds water, embracing it. In fact, the symbol for the $k a$ was a pair of upraised arms, stretched out in a welcoming embrace, yet also raised up in a way that brings to mind the image of a cup ready to be filled. In the same way, the conscious mind can be said to be contained, and therefore shaped, by the unconscious. The conscious has no shape of its own, no unique personality, except as informed through the memory shape of the unconscious; without the unconscious with its memory and emotions, the conscious, although aware, would be as blank and featureless as a sheet of white paper. And just as the $b a$ was thought to animate the $k a$, so too the conscious mind animates and activates the otherwise dormant unconscious. 
During life, the $k a$ dwelt within the heart, and the $b a$ dwelt inside the $k a$. This union of the $b a$ and $k a$ during life was intimate; the two could not be separated prior to death. The $k a$ was the personal possession of the $b a$; they were like two embracing lovers, two conjoined beings (Davies, 1987). The $k a$ was thought to travel away from the body in dreams while the person was alive (Effland, 1999), but such journeys did not sever the connection between it and the ba (Davies, 1987).

The Division of $\mathrm{Ba}$ and $\mathrm{Ka}$ at Death. But after the person died, the $b a$ and $k a$, which until then had known only partnership, functioning for all intents and purposes as a single unit all during the person's life, now found themselves divided, alienated, separated from one another (Watterson, 1984). This abrupt, disorienting division seems to have been associated with the $b a$ experiencing a loss of memory; multiple chapters in the Egyptian Book of the Dead are dedicated to praying that the deceased's memory be returned to him after he has left the body (Budge, 1967). This could this be accomplished only by re-connecting the $b a$ back to the $k a$, which contains the full pattern and record of the person's life, his memories. In fact, all the funerary prayers of ancient Egypt were designed with but a single purpose in mind: to reverse this division and to get the $b a$ and $k a$ to reunite so the deceased could become a completed, perfected being, an aakhu (El Mahdy, 1989).

The Transfiguration of the Aakhu. If this reunion of the $b a$ and $k a$ was successfully accomplished, it was thought, the person would be transformed into an aakhu, something akin to a shining, glorified, immortal angel. Often called an Osiris, meaning one whose parts have been reunited, the aakhu was the true, complete self in its fully awakened, perfected, and whole state after death (Budge, 1967). The word aakhu carried the sense of one who had been "pulled back together," one who was now fully "self-possessed" (Wheeler, 1999), meanings that reflect the reunification of the $b a$ and $k a$, and the reacquisition of one's past memories, personality, and sense of selfidentity that would thereby occur.

The Second Death. But if the $b a$ and $k a$ did not reunite, then the $b a$ was thought to flit away freely and without concern to heaven, where it would still enjoy unlimited freedom and happiness, doing and going where it pleased, and conversing with other $b a$ 's in heaven (Ries, 1987). Meanwhile, the ghostly-appearing $k a$ would remain behind, trapped in a feebleminded (El Mahdy, 1989), cold, hungry, needy, and vulnerable state in the tomb (Budge, 1967). The $k a$ was thought to have 
many regular and pressing requirements after death, but, without the animating mobility it received from the $b a$, its needs went unmet, and it would eventually disintegrate. If the $k a$ was rejoined to its $b a$, the two of them together becoming an aakhu, then all those needs of the $k a$ would be thereby instantly and eternally fulfilled (Budge, 1967). But failing that reunion, the $k a$ would perish in a "second death" that, to the Egyptian, was the worst disaster imaginable (El Mahdy, 1989); the $k a$ would be utterly annihilated, made as if it had never existed (Watterson, 1984).

\section{The Greek Version of the Binary Soul Doctrine}

When one peers back into the dimmest most distant traces of the ancient Greek civilization, one finds the Binary Soul Doctrine already in full flower. In Homer's Iliad and Odyssey, the oldest Greek literary texts, two distinct types of souls are distinguished, the psuche and the thymos. Thought to be free, unencumbered, and immortal, the psuche held the spark of life, and while it could not exit the body without causing the death of the individual, it was thought to be able to reincarnate. And while the psuche was not thought to possess any feelings or emotions, it was thought to be the center of all abstract intellectual thought. The other soul, the thymos, possessed one's feelings, emotions, needs, and urges. After death, the thymos separated from the psuche and was lost (Bremmer, 1987).

\section{The Early Indian Version of the Binary Soul Doctrine}

Vedic India also held that people possessed two soul-like elements, an asu and a manas (Van Nooten and Hilland, 1994). The asu was active, conscious, sentient, and immortal, carrying the spark of life. The manas held the internal feelings, emotions, and subjective perception, providing a person with his or her ability to perceive and comprehend various relationships with others (Mahony, 1987). After death, the $a s u$ could simply reincarnate again, but the manas could be greatly harmed by death; if it separated from the animating and cognizing asu after death, it would become inert and lifeless (Ries, 1987).

\section{The Later Indian Version of the Binary Soul Doctrine}

Modern Hindu philosophy also holds that two nonphysical elements of the self survive the death of the physical body. And again, one of 
these two, the sukshma sharira, often called in English the "subtle," "astral," or "emotional" body, contains one's emotions and memories, while the other, the karana sharira, the "causal" or "mental" body, holds one's rational intellect and independent free will. During life these are deeply integrated deeply, but after death, the two separate, after which the astral body starts to severely deteriorate (Bhattacharyya, 1987).

\section{The Persian Version of the Binary Soul Doctrine}

Ancient Persians also held that the human soul was composed of two twin parts: the urvan and the daena. The urvan was conscious, active, and verbal, and was immortal and unharmed by death. The daena, created or shaped by the thoughts, words, and deeds of the urvan during life, contained the conscience and a perfect mirror image or pattern of the person's self, including a perfect memory of the person's life. During a great Judgment after death, the two often had a great falling out, when the urvan found itself confronted by the full memory record carried within the daena. Immortality required the successful reconciliation of the urvan and daena after death (Ries, 1987).

\section{The Chinese Version of the Binary Soul Doctrine}

Ancient Chinese yin/yang philosophy parallels the Binary Soul Doctrine in many respects, asserting that not merely the human soul, but all reality is based on and comprised of two equal but opposite interplaying forces. Instead of leaving this concept in the abstract, China's Chou dynasty brought it down to the level of the individual, asserting that each person had two distinct souls: one corresponding to the yin force, the other to the yang force (Wei-Ming, 1987). The hun was the yang soul, conscious, active, intelligent, masculine, and dominant. The $p$ 'o was the yin soul, earthy, emotional, only semiconscious, feminine, and passive. After death these two souls parted company; the hun soul left the body unharmed, returning to heaven from whence it came, while the p'o soul would find itself trapped in a dark underground realm in a dim-witted state (Seidel, 1987).

\section{The Hawaiian Version of the Binary Soul Doctrine}

In Hawaii these two souls were called the uhane, which was thought to be masculine, intelligent, and possess free will, and the 
unihipili, which was thought to be feminine, emotional, and possess the memory. If the uhane became separated from the unihipili after death, it would lose its memory, and end up wandering in a great helpless confusion, often going on to reincarnate. The unihipili, meanwhile, would still recall its memories very well, but would become feebleminded, behaving in an automatic and suggestible fashion. The ancient Hawaiian Kahuna sorcerers claimed to be able to control, manipulate, and enslave the separated unihipili souls of the dead, commanding them to do their bidding much as a hypnotist controls the thoughts and actions of his or her subject. And like the Egyptian $a a k h u$, the Hawaiians also named a third, higher kind of soul, the aumakua, which was created out of the two binary souls when they would successfully unite into a singular unit (Long, 1965).

\section{The Hebrew Version of the Binary Soul Doctrine}

Ancient Israel also held that people are comprised of two spiritual elements: a ruwach, commonly translated as "spirit," and a nephesh, commonly translated as "soul." The ruwach was active, strong, conscious, intelligent (Strong, 1984), and communicated with words (2 Samuel 23:2). It was immortal, existing before the person's birth and surviving his or her death unharmed, always "returning to god who gave it" (Ecclesiastes 12:7). But the nephesh, which embodied one's emotions, memories, and sense of self-identity, was vulnerable and could be greatly harmed by death, becoming trapped in a weak and feebleminded state in She'ol, a dark, underground, dreamlike netherworld (Ries, 1987).

\section{The Islamic Version of the Binary Soul Doctrine}

In ancient Islam, the two souls were called the ruh and the nafs, linguistically similar to the Hebrew ruwach and nephesh. Like the Hebrew ruwach, the ruh carried the spark of life, was associated with the rational intellect, and was capable of communication, and like the Hebrew nephesh, the nafs was associated with one's feelings, needs, and desires (Ries, 1987).

\section{The Christian Version of the Binary Soul Doctrine}

Early Christians also distinguished between the soul and the spirit and, as one Biblical passage reveals, it was openly taught in the 
early days of the Church that the soul and the spirit were capable of separating from one another: "The word of God is living and active and more powerful than any two-edged sword, and cuts so deeply it divides the soul from the spirit" (Hebrews 4:12). An archaeological discovery in 1948 raised the intriguing suggestion that the Binary Soul Doctrine may have played a far more central role in early Christian theology than today's culture has been led to believe. A nearly 2000-year-old cache of lost early Christian scrolls was unearthed in Nag Hammadi, Egypt (Robinson, 1977), indicating that early Church teachings once credited great relevance to the distinction and interaction between the soul and the spirit (The Secret Book of James 11:38-39, 12:1-6, in Robinson, 1977). Three lost Christian gospels, the Gospel of Thomas, the Gospel of Truth, and the Gospel of Philip, return again and again to the issue of division, mysteriously insisting that Jesus somehow divided into two halves when He died on the cross (Gospel of Philip 68:26-29, in Robinson, 1977), that all people were in danger of such a division (Gospel of Thomas 11, in Robinson, 1977), that the division of the soul and spirit (Exegesis on the Soul 133:4-9, in Robinson, 1977) or of Adam and Eve (Gospel of Philip 68:22-26, in Robinson, 1977) was the origin of death, and that "making the two one" was key to achieving eternal life (Gospel of Thomas 22, in Robinson, 1977).

\section{Other Western Versions of the Binary Soul Doctrine}

The Mandaean religion, a still-living offshoot of the gnostic branch of early Christianity, believes even today that the living possess both soul and spirit, and that these two elements of the self split apart after death. Three days after burial, Mandaean priests celebrate a ritual called the masiqta, the aim of which is to reunite the soul and spirit in the afterlife, thus creating a new "Lightworld" body for the deceased that will allow him to live among the blessed dead (Buckley, 1987).

Manichaeism, another offshoot of Gnostic Christianity, also believed there were two distinct halves to the human soul. The nous was the half of the self that was immortal, while the psuche was the half that was vulnerable and in danger of being destroyed during the transition of death.

Emmanuel Swedenborg, founder of the New Church, also spoke of two distinct halves to the human soul, calling them the inward and outward thoughts. At death, these two elements part company, according to Swedenborg, and the outward thought, which holds all one's insights and data and the capacity for logical thought, was lost, 
while the inward thought continued on in a dreamlike netherworld (Swedenborg, 1979/1758).

Rudolf Steiner, theologian and founder of the Waldorf Schools for children, also recognized both soul and spirit, and taught that these two permanently part company after death, after which the soul would slowly disintegrate and cease to exist altogether. Again, like so many other traditions did, Steiner viewed the soul much like today's scientists view the unconscious, crediting it with possession of the memory and emotions, and the spirit like the conscious, crediting it with objective, rational thought. But Steiner held that the eventual separation of spirit from soul in the afterlife was a good thing, necessary for the higher evolution of the spirit (Steiner, 1984).

The popular modern psychic James Van Praagh also maintains that discarding half of our being after death is an advantageous eventuality. He teaches that human beings possess two halves to the self, both an astral body and a mental body, which separate at death. The astral body, he maintains, is made up of all one's emotions, yearnings, memories, and desires, while the mental body carries with one's rational, objective, logical thought processes. During life, these two bodies intermingle and are interdependent on one another, making us whole beings, according to Van Praagh. But in death, we completely slough off the emotional body, leaving it behind to disintegrate in an event Van Praagh identifies as the legendary "second death" spoken of in Hindu, Egyptian, and Christian traditions (Van Praagh, 1999). However, while some, such as Steiner and Van Praagh, may hold that discarding the emotional half of the self is necessary and good for one's subsequent spiritual evolution in the afterlife, Leo Buscaglia, America's popular cultural guru on "being fully human," would disagree. Buscaglia has spent his entire public career arguing just the opposite: that one's feelings, emotions, memories, and interpersonal, intersubjective sense are the most valuable aspects of the self (Buscaglia, 1986). If Buscaglia were correct, it seems, no afterlife without these qualities would be worth the bother.

\section{Tribal Versions of the Binary Soul Doctrine}

The belief in a dividing binary soul is also found in many primitive cultures across the globe. The two souls of Inner Asia's Tunguz tribe is a typical example, in which one soul is free and independent after death, returning to heaven to wait until it reincarnates, while the second soul becomes eternally imprisoned in an dark netherworld. The Australian 
aboriginal tribes also believed that people possess two souls, one that reincarnates into another human body after death, and another that takes up eternal residence after death in a dreamlike realm known as the "Dreaming" (Ries, 1987). Africa's Mossi tribe believed that human beings have one masculine and one feminine soul, and that death divides these two apart (Riviere, 1987). Africa's Samo tribe called their two souls the ri and the mere; the ri soul contains the person's thought and life force, reincarnating after death, while the mere soul contains a perfect record of that person's nature and characteristics, and becomes permanently trapped in a netherworld after death (Ries, 1987).

The Binary Soul Doctrine was once extremely widespread in the Americas; tribes from Alaska to South America believed in a "corporeal soul" that gave life, consciousness, and the faculty of movement, and a "free soul" or "dream soul" that would become trapped in the realm of the dead after death. The corporal soul provided the life force, and could not exit the body without resulting in the death of the individual. But the free soul could leave the body during life, and was thought to do so often, such as during dreams, trances, and mystical experiences. Alaska's Inuit believed in two souls, one which held the life force and reincarnated into a new body after death, and another, the tarnneg, or double of the person, which permanently entered a realm of the dead (Ries, 1987). North America's Dakota tribe called their two surviving souls the nagi and the niya. The nagi held the power of movement and independent free will, and after death it could either join the world of the spirits or be forced to wander aimlessly. The niya held the conscience and memory and helped a person to relate to and interact with others. After death, the niya was thought to testify against the other soul in a great Judgment after death, much like the Persian daena and Egyptian $k a$ (Riviere, 1987).

\section{Linguistic Evidence of a Cultural Memory of Binary Souls}

This ancient idea of two dividing souls has been largely forgotten by contemporary cultures. But while modern civilization may have lost sight of dividing souls as a model of death, we have not lost sight of binary souls as a picture of the makeup of a human being. The idea that people are three-part creatures, having one body which holds two soul-type elements, is still a very familiar image, an ancient insight that still lives and breathes in our words. We regularly describe ourselves as having body, soul, and spirit, or body, mind and soul, or body, heart and 
soul, or some other variation of this theme. We are not even sure what we mean by these terms anymore, but we use them nonetheless. Still, most references to "soul" or "spirit" have been generally regarded as pointing to more or less the same thing for much of the last 2000 years. But that may be changing in this century.

\section{The Scientific Version of the Binary Soul Doctrine}

One of the most astonishing facts of this age is that our culture, after thousands of years, has found reason to again resuscitate and embrace the ancient concept of binary souls. Having spent nearly a century applying the most rigorous scientific tests, humanity has again arrived at the conclusion of the ancients: that we are indeed two-part creatures, comprised of a conscious mind and an unconscious mind.

Humanity actually reached this conclusion not once but twice in the 20 th century. In the early 1900 s, Sigmund Freud and Carl Jung first reintroduced and popularized the notion that the human psyche is composed of two distinct parts. Later scientists went on to describe and define those two parts in virtually the same language the ancients used to describe the two souls of the Binary Soul Doctrine: one was active, objective, logical, intelligent, masculine, and had free will, while the other was subjective, emotional, feminine, and held the memory (Jung, 1960). With the advent of neuropsychology over the last 30 years, the basic premise of the two-part mind has been powerfully reinforced and substantiated; the study of the two hemispheres of the brain has again concluded that two entirely separate and distinct minds do indeed coexist in the brain, one residing in the right hemisphere, and one in the left (Ornstein, 1997). Neuropsychologist Fredrick Schiffer (1998) has maintained (Schiffer, p. 79, 80, 84-85):

We have two minds, one associated with each hemisphere... The two minds are different... The dichotomy of mind is entirely normal-it is, in fact, the way we human beings are made... The two minds can cooperate with each other... or they can sabotage each other.... the two minds constantly interact.... Not only have we discovered two intact minds in split-brain research and in psychology, but we have found that in both cases, the two minds seem to interact in similar ways.... A number of authors, including myself, have turned to the split-brain studies to advance the notion that the right hemisphere is the site of the Freudian unconscious... The basic idea emanating from the split-brain studies - that of mental duality-offers a profound foundation for any psychological thinking. (pp. 79-85) 
So, just as Freud and Jung maintained at the beginning of the 20th century, and just like the Egyptians, Greeks, Persians, Chinese, and so many other peoples maintained thousands of years ago, modern neuropsychologists are also finding themselves repeating the same ancient story, perhaps the most ancient of all revelations: that human beings have two minds, or two souls. However, modern scientists have not merely rediscovered humanity's two souls, but have greatly added to the scant information about them that had managed to trickle down to us through history. And what modern scientists have added to our knowledge about the nature of the conscious and unconscious seems to explain a great deal about the afterlife traditions of the ancients, as well as the reports of today's afterlife researchers.

\section{A Pairing of Opposites}

Scientists have taught us that the conscious and unconscious are exact opposites in many respects: the conscious is active, while the unconscious is reactive and responsive; the conscious seems to exercise autonomous free will, functioning under its own initiative and volition, while the unconscious functions automatically and instinctively (Freud, 1965/1932); the conscious is objective while the unconscious is subjective; and the conscious is intellectual while the unconscious is emotional (Jung, 1953). And modern neuropsychologists have added even greater depth to our comprehension of these dynamics, teaching us that the conscious mind is verbally oriented while the unconscious is nonverbal, thinking and communicating via symbols, pictures, gestures, and metaphors (Ornstein, 1997).

Neuropsychologists have revealed that the conscious mind sees the differences and distinctions between things, while the unconscious is geared to do just the opposite: to see the connections, relationships, and similarities between things (Springer and Deutsch, 1985). The conscious sees the trees, the unconscious sees the forest; the conscious reads the text, the unconscious perceives the context; the conscious sees the details, the unconscious sees the meaning (Ornstein, 1997). This division of labor seems to explain why the ancients insisted that only one of their two souls possessed independent free will. Being blind to the differences and distinctions between things, the unconscious does not realize the existence of choices, options, and alternatives, is therefore unable to choose or decide, cannot exercise self-determination, therefore lacks autonomous free will, and thus is like a mindless machine running on automatic. 
Remarkably like the yin and yang of classic Chinese philosophy, the unconscious and unconscious seem to be closely embraced in a dance, with the conscious leading by making new choices and decisions. Whenever the conscious mind initiates a move, the reactive and responsive unconscious makes a corresponding move. Whenever the conscious mind chooses or acts, the unconscious mind reacts immediately and directly to that choice or act, automatically generating its own responses, in the form of feelings, emotions, impressions, and insights, that are then released back into the conscious mind.

The conscious and unconscious are so tightly intertwined in this dance that they give the compelling illusion of existing and functioning as a single unit. Just as one's left and right eyes produce two separate and distinct visual fields that are united and integrated in one's mental experience into a single vision, so too the two halves of the psyche are so intimately integrated together in one's mental experience that they too seem to be a single unit, a single experience, a single self. This illusion of singularity is so persuasive that it has taken our most sophisticated scientific research and analysis to penetrate. Each eye, by itself, only produces a two-dimensional image, but when integrated they produce a new thing that never existed before: a three-dimensional image. In much the same way, each of the two spheres of human consciousness are alone greatly limited and inadequate, but when they are integrated, they produce the fullness of human consciousness: a self-aware individual.

These two halves of the psyche remain bound fully together during life. They are always dancing in unison, and although one or the other may seem to have the upper hand at any given moment, both are always involved in the overall experience we register at any given time. Thus when the conscious mind seems to have full control, such as when one is most fully awake and involved in logical thought calculations, the unconscious is still there in the background, still intimately involved in producing one's psychological experience and mental processes. And in the same way, when one is most deeply asleep and dreaming and the unconscious seems to be in charge, the conscious mind is still also present and actively involved in producing one's experience.

\section{Embodying the Dichotomy Between Form and Substance}

Ancient Egyptians credited the $k a$ or unconscious soul with the ability to assume different forms, and the nature of the unconscious seems to explain this as well: the unconscious excels at form recognition. 
Because the unconscious is designed to recognize the connections, relationships, and similarities between things, one of its jobs seems to be to recognize meaningful patterns within data. In other words, it seems to be the half of the mind that can discern form (Sagan, 1977). The neuropsychological studies of the last 30 years show that the right-brain unconscious is far more adept at recognizing patterns, forms, connections, and relationships than the left-brain conscious (Ornstein, 1997). Thus the classic philosophical dichotomy between form and substance also seems to be embodied within the distinctions between the conscious and unconscious: the conscious is like an eye that only recognizes substance; the unconscious, an eye that only recognizes form.

\section{Embodying the Dichotomy Between} Autonomy and Relationship

Arthur Koestler coined the word "holon" to refer to a thing that is simultaneously both a whole and a part, which, as he pointed out, most things are. Individual atoms, for example, are distinct and autonomous wholes that are, at the same time, also mere parts of molecules, which are themselves parts of whole cells, which are parts of whole organs, which are parts of whole creatures, which are parts of whole families, and so on. These two different natures, wholeness and partness, are always in a state of dynamic conflict: one is concerned with preserving the holon's sense of "wholeness," its independent distinctness and autonomy, while the other is concerned with preserving the holon's sense of "partness," its interdependent, integral relationship to the world around it (Wilber, 1999).

This functional dichotomy of holons is perfectly reflected in the two halves of the psyche. Perfectly performing the functions of "wholenessorientation," the conscious mind tends to recognize the distinctions and differences between things. The conscious mind tends to view itself as independent, separate, and autonomous, complete unto itself. The unconscious mind, on the other hand, seems to perform the functions of "partness-orientation," always focusing on the similarities and relationships between things. Thus, it seems that the two natures of holons have manifested in human psyches as two distinct spheres of consciousness.

Every holon, Koestler realized, is equally dependent on its "wholeness" and its "partness" for its continued survival; if a holon lost either its distinct autonomy or its integral relationship with its 
environment, it would cease to exist. This, of course, has sobering implications for the dividing soul doctrines of the ancients, especially since the conscious seems to embody the function of "preserving wholeness," and the unconscious seems to embody the function of "preserving partness."

\section{The Unconscious as "The Double"}

The unconscious is receptive, a perfect memory machine, forming itself into a flawless record of all of one's experiences, both internal and external, all one's memories, thoughts, deeds, impressions, convictions, desires, dreams, hopes, loves, hates, and so on (Jung, 1960). This may be the origin of the fact that so many cultures, including those of Egypt and Persia, specifically described the unconscious-like soul as being a perfect double or image of the individual.

\section{The Conscience Function of the Unconscious}

Many early traditions (and Jung in the last century) maintained that the unconscious-like soul contained or produced the conscience, an innate moral sense of right and wrong, and the combination of two of the unconscious' chief characteristics, responsiveness and memory, may explain how this conscience function is produced. Whenever the conscious mind makes a new choice or decision, the unconscious automatically reacts by comparing that latest choice or decision with the full gestalt of all that person's memories, all his or her previous thoughts and impressions and decisions. Like a mirror, the unconscious forces us to look back upon ourselves and our own past decisions, conclusions, perceptions, and attitudes. This "conscience" function of the unconscious deceives many into assuming that the unconscious is actively judging our actions and decisions in life; but in reality, the unconscious is, throughout the entire process, functioning automatically, without will or intent. The unconscious merely records all our decisions and conclusions, treating them simply as commands to be followed, carrying them out as a computer carries out its programming. Thus, if the unconscious contains the judgment that a certain act is "bad," and a the person does that "bad" thing, the unconscious will compare the present act and the previous judgment and generate corresponding "bad" or guilty feelings. Like a mirror, the unconscious always responds in kind, good for good and bad for bad. As described below, this conscience function seems to be responsible for 
the "judgment" experience reported during some NDEs, as well as the heavenly or hellish experiences that may follow.

\title{
Life After Death Phenomena and the Binary Soul Doctrine
}

\begin{abstract}
Like two birds of golden plumage, inseparable companions, the individual self and the immortal self are perched on the branches of the selfsame tree.

The former tastes of the sweet and bitter fruits of the tree; the latter, tasting of neither, calmly observes. (Prabhavananda and Manchester, 1948, "Mundaka Upanishad")
\end{abstract}

As curious as it is that so many ancient cultures seem to have known about the conscious and the unconscious, it is even more curious that they all also agreed that these two souls separated at death. The logical question is: what would happen to the conscious and the unconscious if they did separate after death? Where would they be? What would each experience? The answers is that each would lose what the other half gave it, and would be forced to rely exclusively on its own capacities.

The conscious half, then, would lose all its memory, all its emotion, all its subjective sense of connectedness and relationship, all its sense of pattern and context, everything it had previous received from the unconscious. But it would continue to possess its own objective perspective, rational intellect, verbal communication skills, and independent free will volition. On the other hand, an afterdeath division would cause the unconscious to lose the ability for objective, rational, independent thought, its verbal communication skills, and its independent free will ability to make new choices and decisions. It would, however, still retain its subjective perspective, emotions, memory, and ability to perceive patterns, context, connectedness, and relationships.

Many of those ancient cultures held that the conscious-like soul possessing intelligence and free will would reincarnate after death, while the unconscious-like soul having the emotions and the memory would find itself in a dreamlike netherworld experience after death. These scenarios are uncannily close to what modern scientists would predict as likely experiences if the conscious and unconscious did separate after death. In fact, a division of the conscious and unconscious at death would account for the vast majority of reports emerging from modern afterlife research, including NDEs, reincarnation and past-life regression, and apparitions. 


\section{Two Stages of NDEs}

According to Peter and Elizabeth Fenwick (1997), two stages of experience are commonly reported in NDEs, a dark stage followed by a light stage, and these two stages seem to be mirror images of one another in many respects. In the first stage, when the individual has just left the body, the experience is typically described as floating alone within a black void or tunnel, experiencing perfect calmness and peace, a loss of emotional investment in one's own past life, a loss of all sense of connection to anything else, and often a hyperalert awareness with sharply enhanced logic and reason. This first phase of NDEs is often brief, sometimes passing so quickly that it is overlooked in the transition to the more intense and sensational second stage.

Conditions in the second stage seem to be polar opposites of the first: instead of being in total darkness, experiencers are now in brilliant light (Moody, 1977). Instead of floating alone in an empty void, they now are enveloped in a living universe filled with forms of all types. Instead of being entirely unique, they are now interacting with many others like themselves. Instead of noticing a lack of emotion, they now feel intense emotion, usually either the sweetest of joys or the bitterest of miseries. Instead of being objective, they are now subjective. Instead of feeling unconnected to anything, now they feel an intimate connection to their past life, as well as to those they meet in this new realm, and indeed to the entire universe. And instead of experiencing a sharpened sense of logic and reason, they now often seem to exhibit, though without realizing it, a diminished tendency to exercise critical analysis and discriminative reason. In short, the first stage seems to be experienced through the eye of the conscious mind, while the second stage seems to be experienced through the eye of the unconscious mind.

Stage One: Peace in the Dark Void. NDErs often describe stage one as taking place in an absolutely black nothingness, a realm totally devoid of forms or imagery of any kind. They often find that they cannot see anything, including themselves, in this realm of unending emptiness. A strange loss of emotions and a sense of disconnectedness tends to take place during this stage, after leaving the body but before entering the realm of light. Experiencers tend to characterize their psychological state during this phase as one of complete indifference and emotional detachment; despite having just been ripped from their bodies, as well as their family, friends, loved ones, career, and plans for the future, they inexplicably feel no distress or anxiety of any kind over this unforseen development. On the contrary, NDErs often 
mention a deep sense of peacefulness, calm, and serenity during this phase, all of which seems to point more towards an absence of negative emotions than the presence of any positive ones, in sharp contrast to the second phase of NDEs in which experiencers commonly describe extremely intense emotions. The "peace" of this first stage, then, seems to be the interpretation experiencers give to the sudden loss of all subjective emotion and feeling, understandably equating the total absence of anxiety and distress with the presence of deep calm and inner peace. Jenny McMillan's description of this first NDE stage is a typical example of this phenomenon:

I realized that I must be dying and...I didn't mind in the least. I remember being very interested in the experience in a very unemotional academic way and feeling that it was quite an adventure-no regrets at all.... My husband and two-year-old son were everything to me, and I was shocked and amazed at myself for not minding the thought of leaving them, yet I was overwhelmed by a feeling of peace.... I knew how devastated they would be at my death but even this did not really move me. I... felt free of any cares at all.... It was just peaceful and interesting and detached. (Fenwick and Fenwick, 1997, pp. 52-53)

Descriptions of the first stage of NDEs using words such as "detached," "calm," "peaceful," "serene," "dispassionate," "divorced from what was happening," and "release from care" are common. In fact, this detached calm state is the single most common experience in NDEs, being reported by 82 percent of NDErs (Fenwick and Fenwick, 1997). Many have remarked how peculiar this initial reaction seems to be, how illogical that a person who had lost everything most dear would react with a nonchalance.

Almost as common are reports of increased clarity and swiftness of thought during the first stage. Experiencers often mention a heightened sense of objective intellect, feeling more alert, curious, logical, rational, and intelligent than normal (Boldman, 1999; Fenwick and Fenwick, 1997). While NDErs find themselves sharply interested in observing what is taking place during this phase, this seems to be more out of dispassionate academic curiosity rather than any sense of attachment or personal connection (Fenwick and Fenwick, 1997). During the first stage of his NDE, Elias Silver reported: "My mind seemed terribly clear and alert-more so than ever. I felt I was all mind" (Fenwick and Fenwick, 1997, p. 70). And Audrey Organ declared: "I ... had great mental awareness. I had been given ... the magic key to understanding pure logic" (Fenwick and Fenwick, 1997, p. 74). 
What is being reported during the first stage of NDEs seems to be a dramatic reduction of subjective emotion with a corresponding increase in objective analytical logic, exactly the sort of experiences one would expect to be reported by a conscious mind that had suddenly become divorced from its unconscious half. Without the unconscious, it would feel that all its emotions had disappeared, it would no longer be able to appreciate any subjective sense of personal connections of any kind, it would experience utterly no distress on any level of awareness; and because life always contains some degree of anxiety, the sudden unanticipated dropping away of this angst-ridden underlying mental context would be experienced as a profound state of peacefulness.

And without the unconscious, the conscious mind would be unable to recognize shapes, patterns, forms, or images of any kind: it would see only nothingness. On its own, the conscious mind would have no memory of any forms or images, nor any ability for form-, pattern-, or relationship-perception. Without any sense of context, everything it observed around it would seem to be random chaos, and this would explain why experiencers often report floating in nothingness during the first stage of NDEs (as also do some persons hypnotically regressed to a point in time between lives).

Yet despite all these lost abilities, the conscious mind would still remain fully conscious and aware and it would still possess its objective rational intellect and analytical curiosity, abilities that would seem to enhanced and heightened by virtue of no longer being diluted with the unconscious and its emotions and subjective impressions.

In many respects, this dark emptiness resembles the "Clear Light of the Void" mentioned in Buddhist teachings. Buddhist tradition holds that if one can manage to stay in this first stage and avoid slipping along into the second stage of NDEs, one will have achieved enlightenment and will no longer be subject to reincarnation; but if one does slip into the second stage, Buddhist doctrine declares, one will return to the universe of form and manifestation. This dovetails nicely with the theory that the first "dark void" stage of NDEs is the experience of the conscious and the second "realm of light" stage is the experience of the unconscious, for the unconscious is assigned the task of form-recognition in the human psyche (Jung, 1960; Ornstein, 1997; Sagan, 1977) and without the unconscious no form and therefore no manifestation would be possible. Yet if this is so, one is then impelled to question the Buddhist wisdom of remaining in the dark void, thus remaining ever divided, always experiencing the conscious without the unconscious, always experiencing but half of one's full being. 
Stage Two: Joy in the Realm of Light. The second stage of NDEs, in which experiencers report leaving the dark void usually to enter a realm of brilliant living light, tends to be characterized by the presence of tremendously powerful and moving emotions, deep emotional connection to and investment in the experiencer's own past life through a life review, and a suddenly renewed and enhanced sense of connectedness and community with others or, indeed, with the entire universe.

These are precisely the experiences that scientists would predict for an unconscious that found itself no longer united with its conscious mind. Its experience of feeling and emotion would seem greatly enhanced, to the point of seeming absolute and overwhelming. The emotionally based mental input of the unconscious would, for the first time in the person's experience, no longer be capable of being denied, repressed, or rationalized away by the conscious mind, as is always the case to at least some degree during normal adult life. Unbound at last, all the repressed emotions, denied feelings, forgotten memories, rejected insights, and unacknowledged selfjudgments that had piled up within the unconscious over the course of the person's life would spring forth, finally free of the restrictive, repressive, and controlling influence of the conscious mind. The natural characteristics of the unconscious, including emotion, memory, conscience, receptiveness, responsiveness, aesthetic awareness, and form-, pattern-, and relationship-recognition, would define the nature of the experience. But experiencers in the second stage would also exhibit a pronounced loss of certain abilities that correspond to the characteristics of the conscious mind. Without the conscious mind, the unconscious would lose its reason, logic, objective perspective, free will, and verbal communication ability. No longer having any critical, analytical, or discriminative faculties whatsoever, it would be condemned to accept as unquestionable truth virtually all thoughts, suspicions, and impressions passing across the mind's eye. Without its verbal ability, communication would have to take place without words, instead using gestures, symbols, metaphors, analogies, and direct intuitive awareness. Without the conscious mind's objective perspective, one would have a diminished sense of one's own distinct independence, autonomy, and unique identity; the normal defining boundaries between oneself and others would seem diminished, even nonexistent. These are precisely what most experiencers report during the second stage of NDEs. 
Increased Emotion. The first thing that seems to be noticed about the second stage is the intense flood of feelings and emotions that instantly envelop NDErs; most reports describe extremely positive emotions, such as love and joy, but occasionally extremely negative feelings are reported. Experiencers do not seem to report that they felt just "a little bit good" or "a little bit bad"; the feelings experienced during the second stage of NDEs always seem to be at extreme, maximum levels (Atwater, 1994).

This is precisely what one would expect if the unconscious was operating independently of the conscious mind. Without the conscious mind, the unconscious would no longer possess any discriminative capacity; it would no longer be able to distinguish differences between things or appreciate degrees of difference. The unconscious is designed to perceive the similarities between things, not the differences, and so is constitutionally blind to degrees of difference. So if the unconscious was experiencing fear, it would know that fear in its purest, most absolute, and undiluted form. Similarly, if the unconscious felt love, that love would be experienced as infinite and unlimited. And that is precisely the character of the emotions that NDErs tend to report during the second stage of these episodes.

Diminished Reason. If the unconscious was divorced from the conscious mind, it would no longer possess any logical reasoning ability, and second stage reports often suggest a lack of normal deductive logic and analytical reason in experiencers' thought processes. Without the conscious, the unconscious would have no objectivity, which would mean an inability to tell the difference between truth and falsehood. Without the objective conscious, no doubt can be experienced. The objective conscious mind discerns differences and distinguishes between them, accepting one thing while rejecting another. But without the logic and objectivity of the conscious mind, all thoughts running across the screen of the unconscious mind would be accepted equally, each impression seeming to be equally obvious, compelling, and true. And this is precisely the dynamic that seems to take place during the second stage of NDEs.

Absolute Knowledge. NDErs regularly report an experience that seems to be direct and certain knowing (Atwater, 1994); information received in this way is always felt to be 100 percent certain, despite having in no way been questioned, measured, analyzed, or independently verified (Fenwick and Fenwick, 1997). This attribution 
of certainty to one's perceptions is exactly the way the unconscious processes information. It does not critique, analyze, or question it, but accepts it without dispute or hesitation as absolute and obvious truth. When we dream that we can fly or that we are walking naked into our place of business, we do not during the dream question the reality of these impressions, for there is no logic available in our thought processes at the time, no discriminative capacity to raise doubts.

In much the same way, NDErs during the second stage regularly entertain thoughts and impressions that are never questioned. Yet later, when objective logic is brought to bear upon these insights, one finds that some NDE reports contradict others. Some NDErs insist, for example, that they received the "divine truth" that reincarnation is a false teaching (Eadie and Taylor, 1992), while others return from their NDEs carrying the opposite message (Atwater, 1994). Similar contradictions have occurred over other issues as well, such as the existence of the devil (Fenwick and Fenwick, 1997; Williams, 1999).

This loss of one's critical and analytical functions also seems evident in reports of addictive behavior during the second stage of NDEs. Inhabitants of second stage realms seem to remain frozen in whatever behavior patterns they held at the times of their deaths. Even though they no longer possess physical bodies, they still seek to satisfy their physical cravings, seemingly unable to grasp the simple fact that these cravings can no longer be satisfied (Lundahl and Widdison, 1997). Furthermore, there are abundant reports of the recently deceased being unable to grasp that they are dead, despite an abundance of clues (Brown, 1999; Guiley, 1992; Monroe. 1994; Van Praagh, 1999). The living no longer hear or see them, and their spirit bodies pass through the physical objects they try to grasp and the loved ones they try to embrace; yet, despite all this rather compelling evidence, they remain befuddled, seemingly unable to realize they are dead. This loss of analytical reasoning ability is perhaps most obvious in accounts of the less commonly reported second stage world, the hellish Realm of Bewildered Souls (addressed in greater depth below). The inhabitants of this gray netherworld have repeatedly been described as trapped in unpleasant conditions of their own making, which they could escape easily if only they tried. Yet they do not try (Moody, 1977), nor do they seem to grasp the fact that they could end their misery in a moment if only they tried. Such behavior points strongly to a loss of rational intellect, possibly coupled with a lack of independent free will. 
Increased Sense of Connections and Relationships. NDErs commonly report feeling a profound sense of oneness with the whole universe (Fenwick and Fenwick, 1997), and this too is what one would expect if the unconscious was operating independently of the conscious mind. The unconscious is geared to recognize the connections and relationships between things, and the patterns those relationships form. Seeing only connections but never any differences, the unconscious would see the whole universe as a perfectly interconnected, synchronized, and harmonized singularity.

This is the way the unconscious processes information, and the effects of this natural process can easily be observed in dreams, where identities of multiple individuals and blurred and melded into a single dream character (Freud, 1965/1932); it would be nothing unusual for one's Uncle Arthur to also seem to be one's high school Spanish teacher in a dream, even though in real life they had been entirely distinct individuals. In normal life the conscious and unconscious operate together, one pointing out the differences between things, the other highlighting their similarities; only together can they provide us with a balanced and realistic perspective. But without the distinguishing, objective perspective of the conscious mind, the unconscious is blind to all distinctions, divisions, and inequities. On its own, the unconscious would be unable to distinguish between oneself and the rest of the universe, and would meld the two together ("I and the universe are one") by the same inner programming that causes separate identities to blend together in dreams.

Diminished Appreciation of Objectivity. Just as the unconscious is polarized more towards the subjective than the objective, so too the reports from NDErs seem to emphasize and appreciate subjective interpersonal values such as personal relationships, family, love, and patience, while de-emphasizing more objective values, such as worldly and professional accomplishment. In the "real" world both are inescapably interconnected. Yet we repeatedly hear in the life reviews of NDErs that their subjective emotion-based relationships with others are accorded far more meaning and significance than their objective worldly accomplishments, which, as one NDEr reported, "meant nothing in this setting" (Lundahl and Widdison, 1997, p. 263).

Increased Receptivity and Inclusiveness. Because the unconscious does not have any ability for perceiving details or distinguishing the differences between things, it must accept all thoughts equally. If it was operating independently of the conscious mind as the Binary Soul 
Doctrine suggests would be the case, the right brain unconscious would find itself in a state of complete and total acceptance, rejecting nothing: "The right hemisphere has no equivalent of no" (Ornstein, 1997, p. 93).

This is precisely the mindset found to be in operation in most reports of the second stage of NDEs. All people are loved and appreciated and accepted equally, with none being rejected. Even during the life review, when all one's worst thoughts and deeds are displayed, the experiencer still feels loved and accepted unconditionally (Atwater, 1994). The unconscious must accept everyone and everything, without regard to its objective value and worth, due to the way the unconscious is designed to function.

Diminished Separateness and Autonomy. If the unconscious was divorced from the conscious, one would also expect to see a lessening of one's sense of the distinctions between all things, including the distinctions between one person and another, and this too is a regular feature of the second stage of NDEs. Experiencers consistently report that the normal boundaries between themselves and others have faded, in some cases becoming nearly nonexistent (Fenwick and Fenwick, 1997). Instead of retaining their autonomy, they find now that their very psyches have become like a glass house into which anyone and everyone can peer at will. All their thoughts and feelings are exposed to the universe, and nothing is hidden (Moody, 1977): "I had no sense of being separate. I was in the light and one with it" (Grey, 1985, p. 58).

In the second stage, there no longer seems to be any separateness, which is what one would expect to experience if the conscious mind, which provides our ability to perceive separateness and distinctness, was no longer functioning.

Increased Aesthetic Sensitivity. The right brain unconscious, according to modern neuropsychologists, is oriented towards recognizing and appreciating life's more artistic and aesthetic qualities (Ornstein, 1997). Because of this orientation, if the unconscious was separated from the conscious mind, its aesthetic appreciation and artistic sensitivities would seem greatly magnified. This is consistent with the reports of second stage NDEs. Descriptions of the realm of light usually include descriptions of incredibly beauty. Whether the subject of discussion happens to be the buildings, the natural scenery, or even the inhabitants of the realm of light, they are always too beautiful for words, which is what would be expected if one's aesthetic sense was enhanced. In much the same way, observers of the Realm of Bewildered Spirits also experience a similar intensification of their aesthetic sense 
in the opposite direction. Instead of everything seeming impossibly beautiful, everything in that realm seems to be impossibly ugly or horrific (Lundahl and Widdison, 1997). Either way, the aesthetic sense of the observer in the second stage seems to be registering at maximum capacity.

Diminished Verbal Capacity. If the unconscious became alienated from the conscious mind, it would lose all ability for linear thought, and thus all ability to communicate verbally. Again, the weight of the reports suggests that verbal communication ability is greatly diminished during NDEs. Words are seldom used during the second stage of the experience, communication more often occurring through gestures, images, and direct intuitive comprehension (Moody, 1977). And even long after the NDE is over, words seem hopelessly inadequate to describe the experience. The ineffability of the second stage of NDEs is a common finding; researchers have encountered comments like "no words were spoken," "words were not necessary," and "the feeling was indescribable," and the life review is "more often in the form of pictures than verbal memories" (Fenwick and Fenwick, 1997, p. 116).

Increased Sense of Form and Pattern. The fact that the conscious mind has no capacity for perceiving form while the unconscious does explains why the first stage of NDEs includes no perception of any forms, including one's own self (Boldman, 1999), while the second stage is filled with forms of all sorts. But the form perception of the unconscious would also seem to be responsible for another very notable characteristic of the second stage: the feeling that one has "total understanding," perceiving the full scheme of things (Fenwick and Fenwick, 1997): "Everything fitted in, it all made sense... It almost seemed, too, as if the pieces of a jig-saw all fitted together. You know how it is with a tapestry and all the interwoven parts, then when the tapestry's turned over you see how it all fits in place" (Ring, 1980, p. 183). NDErs often return with claims of seeing "the big picture," instantly understanding the grand scheme of reality, understanding how all the pieces to the puzzle of reality all fit together. This would seem to be form and pattern awareness on the grandest scale.

Diminished Memory of NDE Revelations. While the unconscious is the repository of memory, such memories are primarily the records of the data it receives from the conscious mind while the person was awake. The unconscious fares far worse at retaining memory of its own activity than it does at retaining the memory of what the conscious 
mind experiences; the memory of what one did while awake is far more readily accessible than the memories of what one dreams at night. And while the unconscious is always active, always busy with its own tasks, one generally has no memory of this activity of the unconscious. In much the same way that one has trouble remembering these activities of the unconscious, NDErs report similar memory loss of second stage experiences. Again and again, NDErs have reported that momentous insights and revelations were received during the experience ("All knowledge was given to me"), but upon returning to normal consciousness, these invaluable data are entirely missing from memory (Fenwick and Fenwick, 1997). As is so often the case with dream memories, one is left with very strong and compelling feelings and impressions, but very little specific detail. This would make sense from the perspective of the Binary Soul Doctrine; second stage NDE memories would behave like dream memories if both experiences had originated from the unconscious.

The Life Review. If the unconscious found itself separated from the conscious mind, it would seem likely to experience a full life review much like that reported by NDErs. Without the conscious mind, it would no longer be possible for the emotionally based mental input of the unconscious to be denied, repressed, or rationalized in any way. As described above, unbound at last, all the forgotten memories that had built up within the unconscious over the course of the person's life would spring forth, finally free of the restrictive and repressive influence of the conscious mind.

The conscious mind is the half of the psyche that holds the power of autonomous volition, the power to decide and choose. Without that conscious mind, the unconscious could not choose to do anything, and would find itself totally unable to initiate change in any way. It would have nothing to do but fall back deeper and deeper into its own emotions and memories. Being cut off from its own conscious mind, the unconscious would be completely nonreasoning, emotional, subjective, and inward-looking; it would encounter its own memories, including its own long-forgotten or never fully acknowledged feelings and selfjudgments about those memories.

While people are alive, their unconscious minds remain constantly active, constantly reacting to all their conscious choices and decisions, constantly comparing those choices and decisions with one's own inner sense of right and wrong. But, at least while a person is still alive, one can choose consciously to block out those "nagging whisperings" of 
the unconscious soul. People can, and often do, choose to ignore them, pushing these messages out of awareness (Freud, 1965/1932).

But if our unconscious found itself cut off from the conscious mind after death, that conscious mind would no longer be there to repress memories, feelings, and self-judgments. One would no longer be able to hide from those judgments, but would suddenly find oneself face to face with a lifetimes' worth of repressed self-judgments. With no discriminating intellect, one could no longer ignore, deny, or rationalize those memories, feelings, and judgments. This dynamic would explain the sudden, immediate, and total life review and self-judgment that often occurs during the second stage of NDEs. Just as the Binary Soul Doctrine would predict, these life reviews occur suddenly during the second stage of the NDE, simultaneously releasing into full view all the memories of one's life experiences, even one's most private thoughts and feelings.

The Self-Judgment. The judgment that occurs during this review is most typically experienced as being a self-judgment rather than a judgment by a second party (Moody, 1977), just as the Binary Soul Doctrine would anticipate. The dynamics of human psychology suggest that this judgment, although experienced during the NDE, would not actually have its origins in that moment, although it might seem so at the time. Rather, during the flood of memories, one would suddenly realize that one's own unconscious mind had been reactively judging one's choices and actions all along, during every moment of one's life. During the life review, one would finally come face to face with the sum total of all those past judgments about one's own behavior that one's own unconscious had generated over the course of one's life, judgments that were originally refused recognition by the conscious mind. People tend to keep many such self-judgments repressed, never allowing them to enter into their conscious awareness during life, causing these selfjudgments to build up over the years. But after death, when the repressive conscious mind was taken away, all those judgments would be unbound, allowing the entire psychological logjam to rise to the surface of one's awareness in a single great convulsion, finally being acknowledged. This would explain why the life review, which makes all these unconscious thoughts, feelings, and self-judgments starkly apparent, often makes people feel as if they have finally been revealed to themselves as they truly are for the first time (Boldman, 1999). This sense of having been "exposed" is a common theme in the second phase of NDEs; stripped of all one's illusions, denials, and self-deceptions, one 
feels unaccustomedly exposed to oneself, as well as to others (Moody, 1977).

Increased Reactiveness: Heaven and Hell. If those memories, feelings, and judgments were primarily positive, the unconscious, being responsive and emotional, would respond to them by generating positive feelings and emotions. Since the unconscious is also creative, constantly generating images, dreams, and fantasies, the unconscious could then be expected to create images, dreams, and fantasies to give shape to those feelings, emotions, and self-judgments. If those memories, feelings, and self-judgments were primarily positive, it would generate positive images, dreams, and fantasies to give them shape and manifestation. And if the unconscious was in a truly closed system, completely cut off from its conscious half such that no decision-making ability was available, this process would be likely to continue forever. The good feelings and dream images generated by the unconscious would grow ever stronger and more intense, and in the unconscious' self-manufactured dreamworld, it would experience itself to be in heaven. But if those memories, feelings, and judgments were negative, the unconscious would then generate negative feelings, a process which would also continue and compound, becoming ever stronger and more intense, and in that unconscious' self-manufactured dreamworld reality, it would feel itself to be in hell.

Caught in a circular pattern of automatic behavior, such an unconscious soul would review its memories, react to them emotionally, and react to those reactions emotionally as well, all automatically. This process, however, would not necessarily seem to occur slowly or sequentially, since time does not appear to function normally during NDEs (Moody, 1977). Instead, this entire process would seem to occur instantaneously, moving directly from the life review to experiencing the heaven or hellish dreamworld, without any sense of the psychological processes that led from the one to the other. These predictable processes, based on nothing more esoteric than the findings of modern scientists about the nature and workings of the human psyche, duplicate the classic afterlife scenario of an eternal heaven and hell constantly becoming ever more intensely felt and experienced. The pains of hell would grow ever more horrible, the bliss of heaven, ever more delicious.

The "Realm of Bewildered Spirits." Many researchers have described a gray or hellish version of the second-stage NDE realm inhabited by bewildered, confused, and distressed souls (Atwater, 1994; Fenwick and 
Fenwick, 1997; Lundahl and Widdison, 1997; Moody, 1977; Steiger, 1996). These souls display the characteristics one would expect of separated unconscious souls that no longer have access to their rational conscious minds. Unconscious and unaware, these beings possess extremely low intelligence and vitality, appearing "washed out, dull, gray" (Moody, 1977, p. 19), dreary, and confused. These "Bewildered Spirits" show no intellectual curiosity about where they are, nor any inclination for communication, being entirely caught up in their own emotional misery (Lundahl and Widdison, 1997) and unaware of the presence of others (Moody, 1977). George Gallup and William Proctor (1982) described a similar picture of these beings suffering intense emotional unrest compounded by thick confusion. Have the souls in this realm lost all access to their own conscious minds? At least one NDEr described his own conscious mind as too deeply buried within for him to access it during a hellish experience (Fenwick and Fenwick, 1997).

The ghostlike souls in this gray realm seem to be trapped in easily escapable misfortunes (Moody, 1977), situations that they could escape easily if only they tried (Lundahl and Widdison, 1997). But they do not try, and furthermore, they cannot seem to understand that they could escape if only they would try. The inhabitants of this realm seem so utterly convinced that there is no way for them to escape that they do not even try to look for one (Lundahl and Widdison, 1997). This strongly suggests the absence of the conscious human spirit during these experiences; during normal human life, no matter how desperate the situation, the indomitable will of the human spirit refuses to give up entirely. But in the gray realm of the bewildered, where freedom is apparently right at hand, that indomitable will of the human spirit is nowhere to be seen. Such behavior suggests a scenario consistent with the Binary Soul Doctrine: beings with a complete absence of indendent free will and rational intellect.

The heavenly and hellish realms visited during the second stage of NDEs seem, despite first appearances, to have much in common. In both, emotions and credulousness predominate while reason and verbal expression seem diminished. In the realm of light, communication often takes place using gestures, symbols, and direct mental comprehension instead of words; whereas in the hellish realm, communication often seems to be absent entirely (Lundahl and Widdison, 1997). Both experiences are often described as ineffable (Fenwick and Fenwick, 1997).

NDErs have described what seem to be two very different perspectives of the hellish realm, one seen from the inside, and a very different one seen from the outside. Descriptions from inside the Realm 
of Bewildered Souls can be acutely frightening, with horrifying visual imagery (Fenwick and Fenwick, 1997); but descriptions of this place as seen from the outside never seem to include this nightmarish imagery. Instead, NDErs in the realm of light who find they can peer into the Realm of Bewildered Souls describe this realm simply as being gray, dreary, and dull (Moody, 1977), but then paradoxically describe the inhabitants of that realm as experiencing sharp emotional distress, "wailing and full of desperation" (Lundahl and Widdison, 1997), emotions that seem strikingly incongruous with the bland dullness of their apparent surroundings. It is as if the inhabitants of this realm are entrapped in their own private dream fantasies, which causes them to experience these intensely distressing emotions; whereas observers watching from the realm of light cannot see those privately experienced fantasies, but only perceive the anguished emotions experienced by those bewildered souls.

Raymond Moody (1977) noted that these bewildered dead did not seem to be aware of anything, either in the physical world or the spiritual world, but only shuffled about, each experiencing its own dreadful emotions. However, NDErs observing the bewildered souls from outside were using an objective perspective, which suggests that the division of objective conscious and subjective unconscious was not a full and total separation, in which they would have been unable to view anything objectively at all.

Metaphorical Descriptions. If one acknowledges the preponderance of parallels between the descriptions of second-stage NDEs and the characteristics of the right brain unconscious, one is forced to consider the possibility that the entire second stage of the classic NDE is experienced solely by the unconscious while it is in a state of dissociation from the conscious mind. If so, this would require one to reevaluate the second stage "realm of light" descriptions, for the unconscious does not process or relate information the way the conscious mind does. The unconscious is not literal, logical, linear, or rational. It does not think or communicate the way the conscious mind does, and knowing this, one cannot accept its communications at face value the way one does with communications from the conscious mind, which is literal, logical, and rational. Instead, the unconscious mind thinks and communicates with metaphors, symbols, images, gestures, and so on, and any communication or input coming from the unconscious must be viewed as such.

Dreams are communications from the unconscious, messages generated within the unconscious to be released into our conscious 
awareness (Freud, 1965/1932), as are the world's great myths (Campbell, 1949). Both dreams and myths follow the same laws, the same rules of operation in effect within the unconscious: they do not paint a literal picture of what they are trying to communicate, but instead take a nonlinear route, relating their message using metaphors, analogies, symbols, images, gestures, and so on. If, as the evidence suggests, the second stage of NDEs is experienced exclusively by the unconscious half of the psyche, its descriptions of those experiencesthe mental image of the experience that the conscious mind is left with after the experience itself is over-should then be viewed in much the same way people view dreams and myths, as messages that should not be taken literally, but which must be translated and interpreted before they can be fully comprehended.

NDEs as Evidence of Division of Conscious From Unconscious. The two stages of NDEs reflect the two halves of the human psyche, the dark stage bringing the enhancement of the characteristics of the conscious mind and the diminishment of those of the unconscious, while the light stage does the exact opposite. The dark stage brings a decrease in emotion, connectedness, form perception, and subjectivity, and an increase in autonomy, logic, reason, and objectivity, while the light stage brings the exact opposite.

An argument could even be made that the dark stage also includes some memory loss: remembering no wants and needs, one experiences oneself as having no wants, needs, or addictions in the dark stage (Fenwick and Fenwick, 1997). The light stage brings an increase in memory, and as this would of course include the memories of all one's earthly wants, needs, and addictions, one would experience oneself as still having all those wants, needs, and addictions.

There also seems to be some noticeable diminishment of free will in the light stage: those still obsessed with desires for food, drink, sex, or other addictions find themselves unable to break free of those yearnings even though they find themselves no longer able to satisfy them (Lundahl and Widdison, 1997). Such a diminishment of free will would be consistent with such a division, for the conscious mind holds the free will, and on its own, the unconscious would not. On its own, the unconscious could never choose to change its behavior patterns; it could never even grasp the fact that these behaviors were no longer capable of leading to fulfillment.

Detail after detail suggests that the two halves of the psyche are operating independently of one another during these two stages, as if they were, just as the ancients believed, in the process of splitting 
apart from one another in the moments after physical death. But such a splitting is not what most NDErs report, nor what they believe themselves to be experiencing during these episodes. Their impression, rather, is that these two stages, the dark and the light, occur one after the other, in the normal continuous progression of moments in time: first comes the black stage, and then the light stage follows it, as time normally operates (Fenwick and Fenwick, 1997). Yet NDErs themselves contradict this interpretation, consistently insisting that time is not experienced normally during NDEs. In fact, again and again reports declare that "time as we know it" does not exist during NDEs (Fenwick and Fenwick, 1997). If so, then the black stage and the light stage may not necessarily be arranged in the assumed time sequence, but both may in fact be occurring at the same time but independently of one another, just as the Binary Soul Doctrine suggests.

If the conscious and unconscious do split apart from one another during NDEs, why is this not reported? Perhaps because if such a division did occur, neither side would realize it. Most people do not even realize that they have two parts. But more importantly, the nature of the two halves would completely mask any such division that occurred. The conscious mind, stripped of its memory, would not remember that anything had ever been any different, and so, possessing the reason but lacking the necessary data from which it could draw conclusions, it would never become conscious of the change. Meanwhile, the unconscious mind would see the signs, but could not read them; still holding the memory but now stripped of its reasoning abilities, the unconscious would be unable to analyze the data and figure out that anything had changed.

It seems clear, then, that much of the data emerging from NDE research is consistent with the ancient world's conviction that the conscious and unconscious can and often do separate from one another at death. But NDEs are not the only afterlife phenomena that seems to reflect such an afterdeath division; many other categories of afterlife phenomena also seem to carry similarly compelling indications of such a mental rupture.

\section{The Netherworld of Ancient Myth}

If the conscious and unconscious both survived physical death but separated from each other in the process, the unconscious would encounter predictable conditions. It would feel cold, hungry, and empty, lacking the vibrant and fulfilling presence of its conscious mind; it 
would become dim-witted, having lost its intellectual capacities; and losing the animating vigor of that conscious spirit, the source of its strength and vitality while alive, would severely enfeeble it. Being intellectually incapacitated, it might imagine that it had fallen into some murky netherworld far beneath the world of the living, when in fact it had actually descended into the murky recesses in the deepest levels of the unconscious. Submerging deeper and deeper into the foul dregs of that unconscious wasteland might seem like sinking into the miry waters of the great deep itself.

The idea of the land of the dead being an "underworld" is probably the most widespread traditional concept of the afterlife, found in cultures all around the globe (Van Baaren, 1987). Civilizations from the ancient East to the Maori of New Zealand, from the tribes of the Algonquin and the Ojibwa in North America to those of the Zulu, Ashanti, and Dogon in Africa arrived at the same conclusion: that the souls of the dead descend to some dark netherworld located far below the land of the living (Long, 1987). The Vedic legends of early India, for example, described the souls of the dead entering a dark and silent bottomless pit populated by pale, starving, emaciated specters (Van Nooten and Hilland, 1994). Mesopotamian souls also descended to a dreary netherworld of total darkness, silence, immobility, and hunger (Davies, 1987), as were the ancient Greek dead, who were believed to be condemned to a wretched subterranean existence eternally shrouded in mist and shadow. Greek texts described the souls of the dead as weak, cold, joyless, unconscious, and incommunicative (Brandon, 1967). Similarly, the ancient Egyptian underworld was a boundless watery black abyss whose inhabitants were naked, starving, deaf, and blind (Zandee, 1977). In China, the dead were said to spend eternity in a murky subterranean land in a semiconscious state (Seidel, 1987).

Ancient concepts of the netherworld are in close accord with the scenario predicted by the Binary Soul Doctrine. More importantly, this classic vision is not only ancient history; the same sort of vision is reported today. Within a span of two days, according to P. M. H. Atwater, the same hellish NDE vision was independently witnessed by four strangers: "A landscape of barren, rolling hills filled to overflowing with nude, zombie-like people standing elbow-to-elbow doing nothing but staring straight at [the NDErs]" (Atwater, 1994, pp. 36-37).

Today, just as thousands of years ago, the most common characteristics of the hellish vision seem to be lifeless but anxious wraiths in suffocating, dark, barren expanses. The majority of NDErs 
still describe the hell they visit as cold, hard, and empty, with dulled or dimmed light, just as were reported thousands of years ago (Atwater, 1994). Such descriptions are what would be predicted by the Binary Soul Doctrine: the souls of the dead would descend to a lower level, but lower in terms of consciousness rather than geology.

Surprisingly, the hypothesis that the conscious and unconscious separate after death does not lead to an alien or unfamiliar description of the afterlife, but instead describes a familiar picture of the primordial and seemingly universal image of the netherworld. This suggests that these descriptions of the netherworld are not a true or literal picture of the afterlife, but a metaphor. The Binary Soul Doctrine suggests that the ancient traditions of various underworld realms are genuine and valid, but as metaphorical rather than literal reports, as descriptions of an experience of the unconscious that may otherwise be entirely untranslatable and incomprehensible to the conscious mind: “... all along my near-death subjects have insisted that the words they use to describe their experiences are only analogies or metaphors used to indicate experiences that ultimately lie beyond all human language" (Moody, 1977, p. 38).

\section{Reincarnation}

The division of conscious from unconscious seems to have much in common with one of the oldest conceptions of the afterlife, the doctrine of rebirth. Although the conscious would lose its entire memory if separated from the unconscious, it would nonetheless still maintain full control over its own independent volition, remaining free to make new choices and able to move on to fresh new cycles of experience, the recipe for reincarnation.

Such a division would also explain certain strange phenomena that past-life regression subjects have often reported during the time spent between lives. Individuals who have undergone past-life regression, being hypnotically regressed to a point in time between lives, have often reported spending time in an emotionless black void similar to the dark void of the first stage of NDEs. Regression researchers such as Raymond Moody (Moody and Perry, 1991), Brad Steiger (1996), Joel Whitton and Joe Fisher (1986), and many others have all reported regression subjects floating aimlessly between lives, peacefully, totally alone in a calm empty void. Like those who experience the dark void in the first stage of NDEs, these subjects also often report a complete absence of feeling and emotion while in this void (Steiger, 1996). They seem to be 
emotionally vacant, feeling nothing, very calm and unperturbed, not feeling connected to, interested in, or desirous of anything.

\section{The Void Between Lives}

Memory loss often seems to be a part of this experience; many subjects do not remember their own names or anything else about their previous life while they are floating in this void. All they can remember is floating calmly alone in an empty void. Some regression researchers have reported subjects who seemed to remain in such a emotionless, memory-less state for years or decades between lives, never entering into any realm that even remotely resembles an NDE-like heaven or hell (Steiger, 1996). After this NDE-like void, the next thing many regressed subjects recall is reincarnating into a new body, without experiencing anything like the classic "realm of light" of the second stage of NDEs (Steiger, 1996).

Whitton and Fisher (1986) reported that regression subjects often forget who they are between lives, losing all sense of personal identity to become dispassionate observers floating in a limbo without any subjective sense of self. They also reported that many subjects experience a dissociative consciousness after death, in which their minds literally separate into two distinct streams of awareness. The individual, however, is usually only aware of only one stream at any given time (Whitton and Fisher, 1986). Michael Newton (1994) also maintained, based on his study of past-life regressions, that people's souls split into two parts between one life and the next. His subjects reported that half a person's soul often remains behind in the netherworld, in a sort of dormancy or dreaming sleep, while the other half travels back to earth to be reincarnated into another body. One can find this soul-division theme repeated in NDEs as well. Two neardeath experiencers reported by Barbara Rommer (2000), Sadhana and Eve, both seemed to have experienced soul division during their NDEs, and Olaf Sunden also reported his own mind "splitting into two parts" during his NDE (Morse and Perry, 1992, p. 12).

\section{Haunting Ghosts}

If the unconscious was cut off from the conscious mind after death, it would review and re-experience its memories, feelings, and selfjudgments over and over, which explain the automatic sleepwalking 
behavior of haunting ghosts. The unconscious would just keep reexperiencing the same traumas from its past in an endless nightmare of emotions and memories. Haunting ghosts, the most commonly reported type of ghost, display this very behavior, repeatedly reliving their memories, often of some emotionally traumatic event. They seem to possess no objective awareness or rational intellect, almost never noticing the presence of others or of new walls and floor-plans that have been erected in the building since they died (Guiley, 1992). In both ancient and modern reports, the ghosts of the dead are seen wearing the same clothing and hairstyles they wore while alive. Seeming to have lost all verbal communication ability, these sleepwalking ghosts usually cannot be communicated with at all, and in the rare instances when they do communicate, it almost always takes the form of pictures, images, and symbolism, a "right brain" kind of communication, and almost never uses spoken words or written language (Guiley, 1992). The long history of the nonverbal nature of these entities dates back to the souls of the dead in Homer's Iliad, who were portrayed as being unable to speak properly (Bremmer, 1987). These characteristics are consistent with an unconscious mind no longer in contact with its conscious half.

\section{Apparitions of the Dead}

Another type of ghost, often called "apparitions of the dead," are seen usually only by their friends and loved ones. The vast majority of these visits occur in the first year or two after the person has died. These apparitions are very unlike the other types of ghosts in that they usually show no signs of having suffered any mental impairment at all. They seem still to have full use of all their mental faculties: they still possess their memories and sense of self-identity, and they can still think rationally and communicate efficiently and effectively. But one curious element of these apparitions may hold a clue to their nature: the vast majority of these appearances occur very soon after the person's death. Very few occur more than a few years after the death, and practically none occur after 15 or 20 years (Guggenheim and Guggenheim, 1996). There are, of course, notable exceptions to this; apparitions of some religious holy figures have been reported to have been seen century after century. And of all the different types of afterlife phenomena, these religious apparitions are the only ones that seem to hold any promise of true "eternal life," in which a person survives death without suffering any deterioration of his or her mental faculties. 


\section{Reports of Psychics and Mediums}

Modern mediums claim to perceive and sometimes interact with the souls of the dead, and much of what they say about these experiences is consistent with the Binary Soul Doctrine. Psychic Sylvia Brown (1999), medium James Van Praagh (1999), and out-of-body-experience pioneer Robert Monroe (1994) all described souls of the dead who seemed to be suffering from extreme confusion, often unable to perform the elementary deductive logic necessary to figure out that they have passed on. Van Praagh (1999) and Brown (1999) also both maintain that entities in the other world tend to be nonverbal; instead of verbal communication, Brown wrote, spirits and ghosts often communicate by pantomime. This would be consistent with the Binary Soul Doctrine; without the conscious mind, the unconscious would lack linear thought processes, rendering it incapable of both logical reason and verbal communication. Going one step further, Brown (1999), like Edgar Cayce (Bro, 1988) and Steiner (1984) before her, specifically identified the unconscious as the "spirit mind," the mind used in the realm of the dead.

In many respects, Van Praagh's (1999) descriptions of the afterlife are a textbook example of the Binary Soul Doctrine. He wrote that two personal elements survive physical death: an "emotional body" that contains all one's thoughts, emotions, feelings, yearnings, and desires, like the unconscious mind; and a mental body that he associates with a person's data, logic, intelligence, and reasoning abilities, like the conscious mind. But after writing that "these bodies intermingle and are dependent on one another, and make us whole beings" (Van Praagh, 1999 , p. 33), he then described that wholeness being irreversibly shattered after death, the two elements permanently separated, an event he identified as the "second death." The mental body continues on alone after this division, he wrote, leaving behind the emotional body that then begins to deteriorate (Van Praagh, 1999). Similarly, Monroe (1994) also taught that one part of a person would be left behind in the realm of the dead while another part went on to reincarnate, and placed tremendous emphasis on the importance of collecting these lost parts of the self and reintegrating them back into one's present psyche. According to Brown (1999), then, the souls of the dead are dim-witted, nonverbal, and unconscious-dominant; while Van Praagh (1999) agreed that the souls of the dead are dim-witted and nonverbal, but added that during life, people are composed of a rational and an emotional element, which split apart at death. And Monroe (1994) agreed that the souls 
of the dead are dim-witted and divide at death, but added that these divided parts could be reunited and reintegrated at a later point in time. All these descriptions are consistent with the Binary Soul Doctrine.

\section{This Answer From the Ancient World Really Works}

The connections between humanity's afterlife reports and the Binary Soul Doctrine imply that these afterlife phenomena that have been reported down through the ages were predictable through basic psychological dynamics. An afterdeath division of the conscious and unconscious provides a scientific explanation for the commonly reported afterlife phenomena, experiences that seem to be hard-wired into the human psyche. The Binary Soul Doctrine may also solve the riddle of humanity's two conflicting afterlife scenarios: reincarnation vs. heaven or hell. The world has held onto these two seemingly incompatible doctrines because two very fundamentally different afterlife experiences really were being experienced. The soul, or the unconscious, was having one type of experience, and the spirit, or conscious, was having a radically different one. The scientific discovery of the conscious and unconscious and the once-widespread Binary Soul Doctrine which it echoes suggest that human religion began as a science, a discipline that explored the psychological mechanics of an eternal mind that, while it could not truly die, could nonetheless become profoundly fractured.

\section{More Questions}

The Binary Soul Doctrine raises further questions. For instance, if our psyches do divide at death, if the very lens of our perception splits in two, is our entire perception of reality therefore fractured and invalid from that point on? If NDErs are in profoundly dissociated states of consciousness during their experiences, can their reports be trusted? Can either half of the psyche be trusted to provide a valid picture of reality when they are divorced from one another?

One good reason to consider trusting their input might be the obvious parallel between the two halves of the psyche and the two eyes of the face: one integrates the input from both sides of the psyche in much the same way that one integrates the input from both eyes. When a person closes one eye and peers through the other, is that single eye's vision wrong or invalid? Of course not; each eye, on its own, provides valuable 
and accurate data. Yet each eye alone cannot provide as full a picture of reality as the two eyes can together. Each eye alone can only offer a two-dimensional image; only together can the flat two-dimensional inputs of each eye be combined to produce true three-dimensional depth perception. In the same way, I suspect, the experience of each side of the psyche on its own provides us with accurate data; each on its own has an equally valid perception of reality. But just like eyes, which dimension(s) one perceives and experiences depends on whether one is looking only out of one side, only out of the other, or out of both at the same time.

Is the division permanent? That is, when the conscious mind goes on to reincarnate, does the unconscious stay behind in its heaven or hell? If so, then where does the new unconscious for the next lifetime come from? And does the apparent fact that the discarded unconscious from one's previous life seems still to be functioning, actively registering and processing experience, have anything to do with the alreadypsychoactive unconscious of infants? Do people have untold numbers of long-forgotten past-life unconscious souls still actively involved in their own heavenly or hellish experiences deep within their psyches? The early Christian Gnostics seem to have thought so, and made it a prerequisite for salvation to reawaken these past-life selves from their slumbers (Novak, 1997).

What does this division do to the self? During life, human beings are not simple, but complex creatures, formed equally out of two parts. A person is not quite a soul that possesses a spirit, nor a conscious that happens to have an unconscious; instead, a person is a composite creature formed out of the pair. Or is it more correct to say that one's self is not the marriage of these two parts, but rather the fruit of that marriage? A person cannot honestly identify with just one of these parts and deny the other; for just as the two hemispheres of the brain are equal in size, so too the sense and experience of self is equally dependent on both halves of the psyche. The experience of self, one's sense of identity, is born out of the deeply integrated marriage of the two halves of the psyche. Does the disintegration of that integration destroy the self that one experiences oneself to be? Some quotes from NDErs suggest the destruction of the self:

Identity ceases. The "you" that you once were becomes only a memory. (Atwater, 1994, p. 182)

No words were spoken but my predicament was completely understood. I loved my wife more dearly than life itself and I could not 
leave here like this. I knew that we would never meet again because as individuals we would cease to exist. The concept is so very sad and it is utterly inadequate to say that it does not matter. (Fenwick and Fenwick, 1997, p. 108)

Does the division get worse over time? Does the partial deterioration of personal boundaries experienced during NDEs increase to a fuller dissolution of those boundaries once death is complete and irreversible? Both the ancient Greeks and Hebrews seem to have thought so. Do the souls of the dead deteriorate over time, as so many ancient cultures believed? The fact that the vast majority of undivided-psyche apparitions of the dead occur within the first year or two after the individual's death suggest that they do (Guggenheim and Guggenheim, 1996).

Although both groups show some signs of psychological disintegration, the souls in the Realm of Bewildered Spirits seem to be far less psychologically functional, integrated, and whole than those in the Realm of Light. Are there then varying degrees of division? If so, do some people die without dividing at all? Certain reports of NDEs, pastlife regressions, after-death communications, and apparitions of the dead do seem to suggest that some individuals successfully survive the separation from the body without any loss of psychological integration. If it is possible to die without dividing, how might this be accomplished? Is some sort of integration of the conscious and unconscious prior to death the key to preventing this division? Many ancient traditions do suggest this, such as the ancient Egyptian funerary rituals uniting the $b a$ and $k a$, the Taoist emphasis on balancing the yin and yang, and the traditions of Jesus having "made the two one" in various early Christian works. Such integral approaches are growing more common in today's culture, illustrated by recent books such as The Marriage of Sense and Soul (Wilber, 1999), Men Are From Mars, Women Are From Venus (Gray, 1992), and Emotional Intelligence: Why It Is More Important Than IQ (Goleman, 1997).

NDEs, it seems, may also help achieve this integration; experiencers often return with more balanced, healthy, and creative outlooks on life, and sometimes with new psychic abilities (Morse and Perry, 1992). Men end up more in touch with their feminine sides, women with their masculine sides. After their NDEs, many who had previously been more right-brained, intuitive, and unconscious-oriented reportedly find themselves becoming more left-brained, analytical, and consciousoriented; and vice-versa: "The near-death phenomenon seems to stimulate the brain hemisphere that was not previously dominant" (Atwater, 1994, p. 163). 
Both ancient tradition and modern phenomena seem to reflect the same after-death division. Is it coincidence, then, that so many NDErs seem to enjoy a stronger, closer, healthier, more balanced and fruitful relationship between the two sides of their psyches than they had prior to their experiences? This suggests a "rubber band" hypothesis: if NDEs stretch apart the conscious and unconscious, might those two halves then snap back together into a closer, more integrated relationship afterwards? John 11:14-16 seems to suggest such a metaphysical law:

Then Jesus told them plainly, "Lazarus is dead; and for your sake I am glad that I was not there, so that you may believe. But let us go to him." Thomas, called the twin, said to his fellow disciples, "Let us also go, that we may die with him."

as does Tao Te Ching:

What is to be shrunken is first stretched out;

What is to be weakened is first made strong;

What will be thrown over is first raised up;

What will be withdrawn is first bestowed. (Blakney, 1983, p. 36)

The vast majority of humanity's ancient descriptions of the realm of the dead seem to refer to the hellish Realm of Bewildered Souls; yet the vast majority of contemporary NDE reports describe a heavenly realm, with only relatively few describing the hellish scenario. Why is there this discrepancy? Are fewer hellish NDEs being experienced today than in humanity's past, or are fewer being reported than are experienced? If fewer are being experienced than earlier in humanity's history, what caused the change?

\section{Objectivity Versus Subjectivity}

The Buddhist view dismisses the second-stage Realm of Light as illusory, believing instead that the dark void encountered during the first stage of the NDE is the true face of ultimate reality and therefore the most valuable part of the experience. On the other hand, the consensus among contemporary NDErs tends to discount the dark void as a mere passageway, seeing instead the glorious Realm of Light as the ultimate reality and therefore the most meaningful part of the NDE. Finally, the ancient Christian Gnostics insisted that genuine truth cannot be discovered by valuing one polarity above the other, but instead by "making the two one," integrating the two perspectives together. Which of these three perspectives is correct? 
The characteristics of the second phase of the NDE seem to have much in common with the unconscious mind. Should one then conclude that the unconscious mind is the only part of the self that visits and experiences the classic heavenly and hellish realms? Cayce thought so (Bro, 1988); so, it seems, did Rudolf Steiner (1984) and perhaps even Swedenborg (1979/1758).

If so, then this second phase of the NDE is an entirely subjective experience, for the unconscious is entirely subjective. The significance of this conclusion cannot be overstated. In a totally subjective experience, the entire way the rest of the world looks, feels, and is experienced would be completely and utterly dependent on how one feels inside oneself, on how one sees oneself. In the world of the purely subjective, the whole universe is but a mirror reflecting one's own thoughts about oneself. In a world of pure subjectivity, there would be only subject, only self. There would be no object, no "other," no "thing in itself," no independently-existing anything that was truly apart and separate and distinct from the observer.

When one is in the dark void of the first stage of NDEs, on the other hand, one seems to be operating in a purely objective mode. It would only be then, while in that objective mode, that one would actually be capable of recognizing and discerning the existence of any other thing, if in fact any other object besides oneself really existed and was there to see. But instead one sees only nothingness at this unique moment when one is, for the first time in one's entire life's experience, peering out onto the universe exclusively through this objective eye. It is only in the second phase of NDEs, while one is in the subjective mode, and thus really only looking back at oneself the whole time, that anything else seems to exist. This realization compels one to wonder if there really is any other "thing in itself" apart from the observer, or if, as Hinduism and Buddhism have declared all along, one's own consciousness is the only thing that objectively exists in all of reality. Are the two phases of the NDE really just two different ways of looking at the exact same reality? Do the darkness and the light show us two different realities, two distinct realms, or do they both show us the very same "thing in itself," which just happens to seem different because it is being viewed through two very different kinds of observing eyes: the conscious and the unconscious?

What is within us is also without. What is without is also within. He who sees difference between what is within and what is without goes evermore from death to death. (Prabhavananda and Manchester, 1948, "Katha Upanishad") 
When you make the two one, and when you make the inside like the outside, and the outside like the inside, and the above like the below...then you will enter the Kingdom. (Robinson, 1977, "The Gospel of Thomas," p. 121)

\section{References}

Atwater, P. M. H. (1994). Beyond the light. New York, NY: Birch Lane Press.

Bhattacharyya, S. (1987). Indian philosophies. In Eliade, M. (Ed.), Encyclopedia of religion (Vol. 7, pp. 163-168). New York, NY: Macmillan.

Blakney, R. B. (Trans.). (1983). Tao te ching. New York, NY: New American Library.

Boldman, R. (1999). Sacred life, holy death: Seven stages of crossing the divide. Sante Fe, NM: Heartsfire Books.

Brandon, S. G. F. (1967). The judgment of the dead. New York, NY: Scribner's.

Bremmer, J. (1987). Soul: Greek and Hellenistic concepts. In Eliade, M. (Ed.), Encyclopedia of religion (Vol. 13, pp. 434-438). New York, NY: MacMillan.

Bro, H. H. (1988). Edgar Cayce on religion and psychic experience. New York, NY: Warner.

Brown, S. (1999). The other side and back: A psychic's guide to our world and beyond. New York, NY: Dutton.

Buckley, J. J. (1987). Mandaean religion. In Eliade, M. (Ed.), Encyclopedia of religion (Vol. 9, pp. 150-153). New York, NY: MacMillan.

Budge, E. W. (1967). The Egyptian book of the dead: The papyrus of Ani. New York, NY: Dover.

Buscaglia, L. (1986). Personhood: The art of being fully human. New York, NY: Fawcett.

Campbell, J. (1949). The hero with a thousand faces. Princeton, NJ: Princeton University Press.

Crehan, J. (1976). Near Eastern societies. In Toynbee, A., and Koestler, A. (Eds.), Life after death (pp. 97-122). New York, NY: McGraw-Hill.

Davies, S. (1987). Soul: Ancient Near Eastern concepts. In Eliade, M. (Ed.), Encyclopedia of religion (Vol. 13, pp. 431-434). New York, NY: Macmillan.

Eadie, B. J., and Taylor, C. (1992). Embraced by the light. Placerville, CA: Gold Leaf.

Effland, R. (1999). Death: what was it? Mesa, NM: Department of Anthropology, Mesa Community College. Retrieved December 31, 1999 from the World Wide Web: http://www.mc.maricopa.edu/anthro/egypt/cultdeath.html

El Mahdy, C. (1989). Mummies, myth, and magic. New York, NY: Thames and Hudson.

Fenwick, P., and Fenwick, E. (1997). The truth in the light: An investigation of over 300 near-death experiences. New York, NY : Berkley Books.

Freud, S. (1965). New introductory lectures in psychoanalysis. New York, NY: Norton. (Original work published 1932)

Gallup, G., and Proctor, W. (1982). Adventures in immortality: A look beyond the threshold of death. New York, NY: McGraw-Hill.

Gnoli, G. (1987). Iranian religions. In Eliade, M. (Ed.), Encyclopedia of religion (Vol. 7, pp. 277-280). New York, NY: Macmillan.

Goleman, D. (1997). Emotional intelligence: Why it is more important than IQ. New York, NY: Bantam.

Gray, J. (1992). Men are from Mars, women are from Venus: A practical guide for improving communication and getting what you want in your relationships. New York, NY: HarperCollins.

Grey, M. (1985). Return from death: An exploration of the near-death experience. London, England: Arkana.

Guggenheim, B., and Guggenheim, J. (1996). Hello from heaven. New York, NY: Bantam. 
Guiley, R. E. (1992). The encyclopedia of ghosts and spirits. New York, NY: Facts on File.

Jung, C. G. (1953). The collected works of C. G. Jung. Volume 7: Two essays on analytical psychology. Princeton, NJ: Princeton University Press.

Jung, C. G. (1960). The collected works of C. G. Jung. Volume 8: The structure and dynamics of the psyche. Princeton, NJ: Princeton University Press.

Long, J. B. (1987). Underworld. In Eliade, M. (Ed.), Encyclopedia of religion (Vol. 15, pp. 126-134). New York, NY: Macmillan.

Long, M. F. (1965). The huna code in religions. Marina del Rey, CA: DeVorss.

Lundahl, C. R., and Widdison, H. A. (1997). The eternal journey: How near-death experiences illuminate our earthly lives. New York, NY: Warner Books.

Mahony, W. K. (1987). Soul: Indian concepts. In Eliade, M. (Ed.), Encyclopedia of religion (Vol. 13, pp. 438-443). New York, NY: Macmillan.

Monroe, R. A. (1994). Ultimate journey. New York, NY: Doubleday.

Moody, R. A. (1977). Reflections on life after life. St. Simon's Island, GA: Mockingbird Books.

Moody, R. A., and Perry, P. (1991). Coming back: A psychiatrist explores past-life journeys. New York, NY: Bantam.

Morse, M., and Perry, P. (1992). Transformed by the light: The powerful effect of near-death experiences on people's lives. New York, NY: Villard.

Newton, M. (1994). Journey of souls: Case studies of life between lives. St. Paul, MN: Llewellyn.

Novak, P. (1997). The division of consciousness: The secret afterlife of the human psyche. Charlottesville, VA : Hampton Roads.

Ornstein, R. (1997). The right brain. New York, NY: Harcourt Brace.

Prabhavananda, S., and Manchester, F. (Eds). (1948). The Upanishads: Breath of the eternal. Hollywood, CA: Vedanta Society of Southern California.

Ries, J. (1987). Immortality. In Eliade, M. (Ed.), Encyclopedia of religion (Vol. 7, pp. 123145). New York, NY: Macmillan.

Ring, K. (1980). Life at death: A scientific exploration of the near-death experience. New York, NY : Coward, McCann, and Geoghegan.

Riviere, C. (1987). Soul: Concepts in primitive religions. In Eliade, M. (Ed.), Encyclopedia of religion (Vol. 13, pp. 426-431). New York, NY: Macmillan.

Robinson, J. M. (Trans.). (1977). The Nag Hammadi library in English. San Francisco, CA: Harper and Row.

Rommer, B. R. (2000). Blessings in disguise: Another side of the near-death experience. St. Paul, MN: Llewellyn.

Sagan, C. (1977). The dragons of Eden: Speculations on the evolution of human intelligence. New York, NY : Random House.

Schiffer, F. (1998). Of two minds: The revolutionary science of dual-brain psychology. New York, NY: Free Press.

Seidel, A. (1987). Afterlife: Chinese concepts. In Eliade, M. (Ed.), Encyclopedia of religion (Vol. 1, pp. 124-127). New York, NY: Macmillan.

Springer, S. P., and Deutsch, G. (1985). Left brain, right brain. New York, NY: W. H. Freeman.

Steiger, B. (1996). Returning from the light. New York, NY: Penguin.

Steiner, R. (1984). The essential Steiner. (McDermott, R.A., Ed.). San Francisco, CA: HarperSanFrancisco.

Strong, J. (1984). Dictionary of the Hebrew Bible. In The new Strong's exhaustive concordance of the Bible. New York, NY: Nelson Publishers.

Swedenborg, E. (1979). Heaven and hell. New York, NY: Swedenborg Foundation. (Original work published 1758).

Tober, L. M., and Lusby, F. S. (1987). Heaven and hell. In Eliade, M. (Ed.), Encyclopedia of religion (Vol. 6, pp. 237-243). New York, NY: Macmillan. 
Van Baaren, T. P. (1987). Afterlife: Geography of death. In Eliade, M. (Ed.), Encyclopedia of religion (Vol. 1, pp. 116-120). New York, NY: Macmillan.

Van Nooten, B. A., and Hilland, G. B. (Eds.). (1994). Rig veda. Cambridge, MA: Harvard University Press.

Van Praagh, J. (1999). Reaching to heaven: A spiritual journey through life and death. New York, NY: Dutton.

Watterson, B. (1984). The gods of ancient Egypt. New York, NY: Facts on File Publications. Wei-Ming, T. (1987). Soul: Chinese concepts. In Eliade, M. (Ed.), Encyclopedia of religion (Vol. 13, pp. 447-450). New York, NY: Macmillan.

Wheeler, R. L. (1999). Walk like an Egyptian. New York, NY: Allisone Press.

Whitton, J. L., and Fisher, J. (1986). Life between life. New York, NY: Warner Books.

Wilber, K. (1999). The marriage of sense and soul: Integrating science and religion. Boston, MA: Shambhala.

Williams, K. (1999). Near-death experiences and the afterlife. Retrieved December 31, 1999 from the World Wide Web: http $/ /$ www.near-death.com

Zandee, J. (1977). Death as an enemy according to ancient Egyptian conceptions. New York, NY: Arno Press. 